\title{
Notas provisórias sobre a percepção social do corpo ${ }^{1}$
}

\author{
Pierre Bourdieu \\ (Tradução: Ana Maria F. Almeida)*
}

Para compreender os investimentos dos quais o corpo é objeto (se pensamos apenas nos custos em termos de tempo, energia, dinheiro; em estratégias destinadas a transformar o corpo, a aproximá-lo da forma tida como legítima; em maquiagem ou roupas, dieta ou cirurgia estética, para torná-lo apresentável ou representável), é preciso relembrar certas proposições que são esquecidas, por serem evidentes. 0 corpo, como forma perceptível, "produzindo, como se diz, uma impressão" (aquilo que a linguagem comum chama de "físico" e que compreende, ao mesmo tempo, a conformação propriamente física do corpo e a maneira de se portar aí expressa), é, de todas as manifestações da "pessoa", aquela que se deixa menos e menos modificar com facilidade, provisória e, sobretudo, definitivamente. Ao mesmo tempo, é aquela que é socialmente encarregada de significar o mais adequadamente, porque alheia a toda intenção de significar, o "ser profundo", a "natureza” da pessoa². 0 corpo funciona, portanto, como uma linguagem que fala de nós mais do que falamos sobre nós; uma linguagem da natureza, na qual se trai, ao mesmo tempo, o que está mais escondido e o que é mais verdadeiro. Porque o corpo é aquilo que há de menos controlado e controlável conscientemente; aquilo que contamina e sobredetermina, com suas mensagens percebidas ou não percebidas, todas as expressões intencionais, a começar pela fala³.

Mas essa linguagem da identidade natural (do “caráter") é, de fato, uma linguagem da identidade social, naturalizada dessa maneira (na forma, por exemplo, de vulgaridade ou de distinção "na-
* Faculdade de Educação, Universidade Estadual de Campinas (Unicamp), Campinas, São Paulo, Brasil. aalmeida@unicamp.br
1. Os editores agradecem a Jerôme Bourdieu, a Franz Shultheis e à Fondation Pierre Bourdieu, por autorizarem a tradução e a publicação deste artigo na Pro-Posições.

2. Esse é o postulado da correspondência ou do paralelismo entre o "físico" e a "moral" que se encontra no princípio do conhecimento prático ou racionalizado, permitindo associar as propriedades "psicológicas" ou "morais" aos indícios fisionômicos.

3. 0 corpo fala, mesmo quando não queremos - por exemplo, nos primeiros contatos, quando, como já foi mostrado, a prudência impõe uma restrição na comunicação, pelo recurso às banalidades e aos lugares comuns. 
tural”); portanto, legitimada. Quase não há necessidade de lembrar que o corpo, naquilo que ele tem de mais natural na aparência, isto é, nas dimensões de sua conformação visível (volume, tamanho, peso, etc.), é um produto social. A distribuição desigual, entre as classes, das propriedades corporais se realiza por meio de diferentes mediações: as condições de trabalho (com as deformações, as doenças, ou mesmo as mutilações que the correspondem) e os hábitos em termos de consumo que, como dimensões do gosto e, portanto, do habitus, podem se perpetuar para além de suas condições sociais de produção $0^{4}$. As diferenças de pura conformação são sobrepostas pelas diferenças de hexis, de "cuidado": na maneira de portar o corpo, de se portar e de se comportar, por meio da qual se exprime toda a relação com o mundo social (na medida em que a relação com o próprio corpo é, como veremos, uma maneira particular de experimentar a posição no espaço social, pela experiência da distância entre o corpo real e o corpo legítimo). Tais diferenças de conformação são sobrepostas também, claro, pelo conjunto dos tratamentos intencionalmente aplicados a todo aspecto modificável do corpo e, em particular, pelo conjunto das marcas cosméticas (cabeleira, barba, bigode, costeletas, etc.) ou de vestimentas que, a depender dos recursos econômicos e culturais que podem ser investidos, são também marcas sociais, cujo sentido e valor residem na posição que ocupam no sistema de sinais distintivos que elas constituem - sistema que é, ele próprio, homólogo a um sistema de posições sociais. 0 conjunto dos sinais distintivos que constituem o corpo percebido é o produto de uma fabricação propriamente cultural. Tendo como efeito distinguir os indivíduos - mais exatamente, os grupos - pelo grau de cultura ou, mais precisamente, pelo grau de distância com relação à natureza, [tal fabricação] parece encontrar seu fundamento na natureza, isto é, no gosto, [na medida em que] visa a exprimir uma natureza, porém

4. É por isso que o corpo designa não apenas a posição atual, mas também a trajetória. cultivada. Não há sinais propriamente "físicos", e a cor e a espessura do ba- 
tom, a configuração de uma mímica, a forma do rosto ou da boca, são imediatamente vistas como indícios de uma fisionomia "moral”, socialmente caracterizada, quer dizer, [indícios] de estados de espírito "vulgares" ou "distintos", naturalmente "natureza" ou naturalmente "cultivados".

Produtos sociais, as propriedades corporais são apreendidas por meio das categorias de percepção e dos sistemas de classificação social, que não são independentes da distribuição das diferentes propriedades entre as classes sociais: as taxonomias em vigor tendem a contrapor, hierarquizando-as, as propriedades mais frequentes entre os dominantes (isto é, as mais raras) às mais frequentes entre os dominados ${ }^{5}$. A representação social do próprio corpo, com que cada agente social deve contar - e isso desde sua origem - para elaborar sua representação subjetiva de seu corpo (e, mais profundamente, de sua hexis corporal), é obtida, assim, pela aplicação de um sistema de classificação social, cujo princípio é o mesmo dos produtos sociais aos quais tal sistema se aplica ${ }^{6}$. Assim, os corpos teriam todas as chances de receber um preço proporcional à posição de seus donos na estrutura de distribuição de outras propriedades fundamentais, se a autonomia da lógica da hereditariedade biológica em relação à hereditariedade social, às vezes, não oferecesse, aos que são menos privilegiados em todos os outros aspectos, as propriedades corporais mais raras, por exemplo, a beleza (que chamamos às vezes de "fatal", porque ela ameaça a ordem estabelecida) e se, inversamente, os acidentes da biologia às vezes não privassem os "grandes" dos atributos corporais de sua posição, como a altura e a beleza.

0 fato de que a distribuição das propriedades corporais (altura, força, beleza, etc.) seja parcialmente independente da distribuição das propriedades que comandam a posição na hierarquia social não autoriza, de forma alguma, que se trate como alienação genérica, constitutiva do "corpo

5. Isso quer dizer que as taxonomias aplicadas ao corpo percebido (gordo/magro, forte/fraco, grande/pequeno, etc.) são, como sempre, ao mesmo tempo arbitrárias (a ideia de beleza feminina pode estar associada, em contextos econômicos e sociais diferentes, à gordura ou à magreza) e necessárias, isto é, fundadas na razão específica de uma ordem social determinada.

6. Tomadas em sua forma fundamental, a maior parte das oposições que funcionam no terreno da moral e da estética se aplicam diretamente sobre o "físico", como pesado/leve, grosso/fino, grande/pequeno. 
para o outro", a relação dos agentes com a representação social de seu corpo - esse "corpo alienado" evocado pela análise essencialista, corpo genérico como a "alienação" que acontece com todos os corpos -, quando ele é percebido e nomeado, logo objetivado pelo olhar e pelo discurso dos outros ${ }^{7}$. 0 corpo socialmente objetivado é um produto social que deve suas propriedades distintivas a suas condições sociais de produção, e o olhar social não é um simples poder universal e abstrato de objetivação, como o olhar sartriano, mas um poder social, que sempre deve uma parte de sua eficácia ao fato de que ele encontra, naquele ao qual se aplica, o reconhecimento das categorias de percepção e de apreciação que lhe são aplicadas. A experiência, por excelência, do "corpo alienado", a vergonha, e a experiência oposta, o desembaraço, são evidentemente propostas com graus de probabilidade desiguais aos membros das diferentes classes sociais; elas supõem agentes que, oferecendo o mesmo reconhecimento à mesma representação da conformidade e da manutenção da ordem legítima, são desigualmente armados para realizá-la: as chances de viver o próprio corpo sob o modo da graça e do milagre contínuo são tão maiores quanto o conhecimento é uma medida de reconhecimento. Inversamente, a probabilidade de experimentar o corpo (ou a língua) sob o signo do mal-estar, da vergonha, da timidez é tão mais forte quanto mais forte é a discrepância - como acontece com os recém-chegados que aspiram a chegar, burgueses e pequeno-burgueses - entre o corpo ideal e o corpo real, entre o corpo sonhado e o looking-glass self, como se diz às vezes, que refletem a reação dos outros. Isso explica por que, ainda que os pequeno-burgueses dela não detenham nenhum monopólio, a experiência pequeno-burguesa do mundo social é, primeiro, a timidez, o embaraço, o mal-estar daquele que se sente traído pelo seu corpo e pela sua linguagem e que, ao invés de se engajar no seu corpo ou na sua

7. SARTRE, Jean Paul. L'être et le néant. Paris: Gallimard, 1943. p. 404-427. linguagem, os vê como se estivesse do lado de fora, com os olhos dos outros, 
se supervisionando, se corrigindo, se recuperando. Assim, por suas tentativas desesperadas para se reapropriar do seu corpo alienado, dá precisamente lugar à apropriação (ele faz demais, e sua hipercorreção o trai tanto quanto suas inabilidades). Por oposição à timidez, que, não obstante, faz existir o corpo objetivado, aprisionado no destino da percepção e da enunciação coletiva (basta pensar nos sobrenomes e nos apelidos) e é traída por um corpo submetido à representação dos outros, inclusive em suas reações passivas e inconscientes (nós nos sentimos corar), [encontra-se] o desembaraço, esse tipo de indiferença ao olhar objetivante dos outros, que neutraliza seus poderes. Ele supõe a segurança que advém da certeza de poder objetivar essa objetivação; apropriar-se dessa apropriação; impor as normas de percepção do seu corpo - em suma, de poder dispor de todos os poderes que, mesmo quando asilados no corpo e tomando emprestadas suas armas específicas, como o porte ou o charme, lhe são essencialmente irredutíveis ${ }^{8}$. 0 charme e o carisma designam, com efeito, o poder de um agente de se apropriar do poder que detêm outros agentes (indivíduos isolados ou amplos coletivos) de se apossar de sua própria verdade. Ou, em outros termos, o poder de impor, como representação objetiva e coletiva de seu próprio corpo e de seu próprio ser, a representação que ele próprio faz deles. [Ou ainda,] o poder de conseguir que o outro, como no caso do amor ou da fé, abdique do seu poder genérico de objetivação, para delegá-lo àquele que dele é objeto e que se encontra, assim, constituído em sujeito absoluto, sem exterior (porque ele é o outro), plenamente justificado a existir, legitimado. 0 chefe carismático consegue ser, para o grupo que o faz, aquilo que ele é para si mesmo, ao invés de ser para ele mesmo, como é o caso dos dominados na luta simbólica, aquilo que ele é para o outro. Ele “faz”, como se diz, a opinião pública que o faz; ele se constitui como incontor-

8. É assim que se deve compreender o resultado da experiência de Dannenmaier e Thumin, na qual os sujeitos, convidados a avaliar de memória o tamanho de pessoas com as quais tinham alguma familiaridade, tendiam a superestimar a altura daquelas que detinham mais autoridade (DANNENMAIER, Wiliam D.; THUMIN, Frederick J. Authority Status as Factor of Perceptual Distortion in Size. Journal of Social Psychology, n. 63, p. 361-365, 1964). Tudo leva a pensar que a lógica que conduz a perceber os "grandes" como maiores se aplica de maneira muito geral, e que a autoridade, de qualquer tipo, guarda um poder de sedução que seria ingênuo reduzir ao efeito de uma servitude interessada. Daí porque a contestação política sempre usou a caricature, deformação da imagem corporal, destinada a romper o charme e a tornar ridículo um dos princípios do efeito de imposição da autoridade. 
nável, sem exterior, como absoluto, por um simbolismo do poder que é constitutivo do seu poder, já que ela permite a ele produzir e impor sua própria objetivação.

No entanto, contrariamente a tudo que poderia sugerir a analogia do charme e do carisma e toda a teoria psico-sociológica da imagem corporal (body image), que só se torna autoridade - quase sempre reduzida a uma ascendência "pessoal" -, por acidente, as lutas por imposição das normas de percepção e apreciação do corpo não se reduzem às lutas interpessoais, nas quais toda a verdade residiria (como também para os interacionistas) na estrutura da interação. Nós temos condições de falar do "corpo alienado", se percebemos que a definição do corpo legítimo, como realização da identidade inseparavelmente sexual e social, é um objeto de lutas entre as classes: trabalhar para impor ou para defender um sistema particular de categorias sociais de percepção e de apreciação da identidade pessoal é sempre se esforçar para fazer reconhecer a legitimidade das categorias distintivas que portamos, como indivíduos ou como membros de um grupo e do estilo de vida no qual elas se inserem. 0 proselitismo que leva as novas frações da burguesia (e da pequena burguesia) a erigir em norma universal o seu modo de vida e, em particular, os usos do corpo, só pode ser compreendido completamente a partir da intenção, inconsciente mesmo, de produzir a necessidade de seus próprios serviços (dietas, ginásticas, cirurgias estéticas, etc.) ou de seus próprios produtos, ao fazer reconhecer a representação do corpo que eles encarnam (porque detêm por definição os meios de realizá-lo), além dos limites de suas condições de realização, e

9. Pode-se encontrar uma análise das condições de produção e de imposição da nova moral dominante em diferentes trabalhos anteriores (Bourdieu, Pierre; Delsaut, Yvette. Le couturier et sa griffe. Contribution à une théorie de la magie. Actes de la recherche en sciences sociales, n. 1, p. 7-36, fev. 1975 ; Bourdieu, Pierre; Saint Martin, Monique. Anatomie du goût. Actes de la recherche en sciences sociales, n. 5, oct. 1976.). engendrando, assim, a distância entre a norma e a realidade, entre o corpo ideal e o corpo real ${ }^{9}$. As lutas entre as classes têm também como objetivo a dominação simbólica (que pode se realizar por meio do proselitismo o mais altruísta) ou, o que significa exatamente o mesmo, o sentimento de 
legitimidade, a certeza de estar plenamente justificado a existir: o lucro principal que tiramos ao nos apresentar como exemplo consiste em nos sentirmos exemplares.

Mas isso significa também que a definição dominante do corpo e de seus usos exerce o seu efeito específico de desapossamento apenas quando não é percebida como tal, isto é, apenas quando é reconhecida, seja por meio da vergonha corporal ou [da vergonha] cultural. Como se pode ver no caso-limite dos camponeses, a imposição do estilo de vida dominante e da representação legítima do corpo ameaça as condições específicas de sua reprodução (com o [consequente] celibato dos responsáveis pelo estabelecimento agropecuário familiar $^{10}$ ) e sua própria existência como classe capaz de definir, ela própria, os princípios de sua identidade ${ }^{11}$. É, sem dúvida, um dos últimos refúgios da autonomia das classes dominadas, sua capacidade de produzir, elas mesmas, sua própria representação do homem bem-sucedido, que é ameaçado pela imposição da nova definição do corpo e dos usos deste. Da mesma maneira como é todo o modo de vida camponês que é atacado, quando se questiona a maneira como porta o seu corpo e como se comporta com ele, é um dos princípios da visão autenticamente popular que estaria ameaçado, se chegássemos a atacar a adesão dos membros das classes trabalhadoras aos valores da virilidade que são uma das formas mais autônomas da consciência que têm de si mesmos como classe $^{12}$; [ou] se, em outros termos, sobre esse ponto decisivo que é a imagem do corpo, fosse possível garantir que a classe dominada se apreendesse como classe apenas a partir do olhar dos dominantes, isto é, em relação à definição dominante do corpo e de seus usos ${ }^{13}$.

10. No original, chefs d'exploitation, categoria estatística do INSEE, traduzida aqui por categoria correspondente do IBGE (N.T.).

11. BOURDIEU, Pierre. Célibat et condition paysanne. Etudes rurales, n. 5-6, p. 32-136, 1962.

12. 0 lugar que cabe à virilidade, na representação que os membros das classes populares fazem de sua identidade, entendida seja como força e combatividade (e também como coragem e resistência ao sofrimento) ou como potência sexual, guarda, sem dúvida, uma relação inteligível com o fato de que, na luta de classes, as classes populares não têm outras armas, a não ser a retirada da força de trabalho e da força de combate. (A referência à divisão de trabalho entre os sexos que conota a representação da identidade pessoal e coletiva - no caso em que um trabalhador, ao classificar profissões, coloca na mesma classe todas as profissões não manuais, dizendo, "são todos bichas" [touts les pedés, no original], evoca menos a dimensão propriamente sexual da prática do que as virtudes e as capacidades associadas estatutariamente aos dois sexos, quer dizer, a força ou a fraqueza, a coragem ou a covardia, mais do que a potência e a impotência, a atividade e a passividade).

13. Nesse terreno, como em muitos outros tão importantes, que não são constituídos politicamente, é excluída toda resistência coletiva à imposição que conduziria ou a constituir como valor as propriedades negativamente avaliadas pela taxonomia dominante (segundo a estratégia black is beautiful), ou a criar novas propriedades positivamente avaliadas. Resta, portanto, aos dominados, apenas a alternativa da fidelidade a si mesmo e a seu grupo (sempre exposta ao risco da recaída na vergonha de si mesmo) e do esforço individual para assimilar-se ao modelo dominante, que é o próprio oposto de uma ambição de controle coletivo da identidade social (do tipo daquela perseguida pelas feministas americanas, quando elas pregam o natural look). 
O que está em jogo, nessa luta, é a transformação dessa dimensão fundamental da personalidade social, que é a hexis corporal, pela transformação das condições sociais que a produzem (ou, pelo menos, daquilo que pode ser mudado sem mudança profunda da ordem social, a saber, a divisão sexual do trabalho e a divisão do trabalho sexual). A relação com o corpo não se reduz a uma "imagem do corpo", representação subjetiva (fala-se quase que indiferentemente de body image e de body concept) que seria constituída, essencialmente, a partir da representação objetiva do corpo produzida e refletida pelos outros ${ }^{14}$. Com efeito, os esquemas de percepção e de apreciação nos quais um grupo deposita suas estruturas fundamentais (como grande/pequeno, fino/grosso, forte/ fraco, etc.) se interpõem desde a origem entre todo agente e seu corpo, porque as reações ou as representações que este suscita nos outros são, elas mesmas, engendradas segundo esses esquemas: uma reação verbal ou corporal determinada pelas oposições grande/pequeno e masculino/feminino (como todas as manifestações expressas na forma "ela é muito grande para uma menina"15) é uma ocasião de adquirir,

14. A psicologia social situa quase sempre a dialética da incorporação no nível das representações com a sequência body image (ou body concept) como feedback descritivo e normativo refletido pelo grupo (pais, pares, etc.), self-image ou looking-glass self, imagem que um agente tem dos seus efeitos sociais (sedução, charme, etc.) e que implica um grau determinado de self esteem (essa redução deriva, por um lado, do fato de que que a psicologia social considera em abstrato o grupo dos agentes em interação, situado fora do espaço social, esquecendo que toda a estrutura social está presente nas categorias de percepção e de avaliação, isto é, na imagem legítima do corpo.

15. Pode-se pensar também em todo julgamento de forma - "é chato para uma menina" (apresentar uma cicatriz que enfeia ou ser feia) ou "não é grave para um menino" - que afirma a hierarquia dos princípios de classificação próprios a cada sexo (forte/fraco, grande/pequeno para um homem; bonito/feio, grande/pequeno, mas funcionando no sentido inverso para uma mulher). inseparavelmente, os esquemas (que, devolvidos pelo próprio sujeito sobre seu próprio corpo, produzirão, e de maneira durável, a mesma reação) e a experiência prática (que não tem nada de "representação") do próprio corpo que eles proporcionam (a aplicação dos esquemas fundamentais ao próprio corpo e, em particular, às partes do corpo as mais pertinentes do ponto de vista desses esquemas, é, sem dúvida, por causa dos investimentos de que o corpo é objeto, uma das ocasiões privilegiadas de incorporação 
desses esquemas). A experiência prática do corpo, que engendra os esquemas fundamentais (forma incorporada das estruturas as mais fundamentais de um universo social, a saber, as estruturas da divisão do trabalho - entre elas a divisão do trabalho entre os sexos) e que é reforçada, sem cessar, pelas reações a ele próprio, produzidas segundo os mesmos esquemas, é um dos princípios de constituição de uma relação durável e generalizada com o corpo, que define propriamente a hexis corporal. Essa relação com o corpo, que é progressivamente incorporada e que dá ao corpo sua fisionomia propriamente social, é uma maneira global de portar seu corpo, de o apresentar aos outros, e exprime, entre outras coisas, uma relação particular - de concordância ou de discordância - entre o corpo real e o corpo legítimo (tal como ele se define por uma classe particular de esquemas de percepção) ou, se preferimos, uma antecipação inconsciente das chances de sucesso da interação que contribui para definir essas chances (pelos traços comumente descritos como segurança, confiança em si, etc. ${ }^{16}$. Porque os esquemas de classificação social por meio dos quais o corpo é apreendido e apreciado na prática são sempre duplamente fundados na divisão social e na divisão sexual do trabalho, a relação com o corpo se especifica segundo os sexos e segundo a forma que reveste a divisão do trabalho entre os sexos, em função da posição ocupada na divisão social do trabalho: assim, a oposição entre o grande e o pequeno, que, como numerosas experiências mostraram, é um dos princípios fundamentais da percepção que os agentes têm de seu corpo e também de toda a sua relação com o corpo ${ }^{17}$, se especifica segundo os sexos, que são, eles próprios, pensados segundo essa oposição (a representação dominante da divisão do trabalho entre os sexos acorda ao homem a posição dominante, aquela do protetor que envolve, supervisiona, olha de

16. A instauração de uma relação entre desconhecidos (sobretudo de sexos diferentes) é uma ocasião privilegiada de ver funcionar essa antecipação das chances objetivas de sucesso de que dependem, por causa do risco implicado em toda instauração de uma relação social, a existência mesma da relação e suas chances de ser bem-sucedida.

17. Não há nada de mais revelador da relação com 0 mundo social e do lugar que alguém aí se atribui do que o lugar em que coloca seu próprio corpo, o lugar que ocupa (realmente ou potencialmente) com seu próprio corpo. Sobre esse ponto, consultar: FISCHER, Seymour; CLEVELAND, Sidney. Body Image and Personality. Princeton: New York, Van Nostrand, 1958. 
cima, etc. ${ }^{18}$. E tudo indica que a oposição, assim especificada, assume formas diferentes segundo as classes, isto é, segundo a força e o rigor com que a oposição entre os sexos é afirmada nas práticas ou nos discursos (a partir da alternativa distinta - "ser um cara" ou uma "bicha" - até o contínuo) e segundo as formas que devem revestir o compromisso inevitável entre o corpo real e o corpo legítimo (com as propriedades sexuais que lhe são atribuídas por uma classe social), para se ajustar às necessidades inscritas na condição de classe.

18. Segundo uma observação tomada de empréstimo a Seymour Fischer, os homens tendem a se mostrar insatisfeitos com partes de seus corpos que eles consideram "muito pequenas", enquanto as mulheres dirigem suas críticas principalmente às regiões de seu corpo que lhes parecem "muito grandes". 
258 